\title{
Control of Secretion by Temporal Patterns of Action Potentials in Adrenal Chromaffin Cells
}

\author{
Kailai Duan, ${ }^{\star}$ Xiao Yu, ${ }^{\star}$ Chen Zhang, and Zhuan Zhou \\ Institute of Neuroscience, Shanghai Institutes for Biological Sciences, Chinese Academy of Sciences, Shanghai 200031, China
}

\begin{abstract}
Action potentials (APs) are the principal physiological stimuli for neurotransmitter secretion in neurons. Most studies on stimulussecretion coupling have been performed under voltage clamp using artificial electrical stimuli. To investigate the modulatory effects of AP codes on neural secretion, we introduce a capacitance method to study AP-induced secretion in single cells. The action potential pattern was defined by a four-parameter "code function:" $F(n, m, f, d)$. With this method, cell secretion evoked by stimulation with an AP code was quantified in real time by membrane capacitance $\left(C_{\mathrm{m}}\right)$ in adrenal chromaffin cells. We found, in addition to $\mathrm{AP}$ frequency $(f)$, for a given number of APs, another parameter of the AP code, the number of AP bursts $(m)$ in which the set of APs occurs, can effectively modulate cell secretion. Possible mechanisms of the $m$ effect are depletion of the readily releasable pool and inactivation of $\mathrm{Ca}^{2+}$ channels during a burst of APs. The physiological $m$ effect may play a key role in AP-mediated neural information transfer within a single neuron and among the elements of a neural network.
\end{abstract}

Key words: action potential; code; secretion; capacitance; calcium; patch-clamp; chromaffin cell

\section{Introduction}

The action potential (AP) is the fundamental electrical signal of neurons. Because there are many types of neurons, which express distinct combinations of ion channels (Hille, 2001), the variety of AP patterns is countless (Kandel et al., 2000). Depending on presynaptic inputs, different AP patterns are generated even in a single neuron (Sherman, 2001). Thus, the functions of different AP patterns raise an interesting question.

An AP pattern (or AP code) consists of a group of APs in a particular time series. The simplest code consists of APs repeated at a fixed frequency. This AP code can be described by just one parameter, the frequency. In our previous studies, we demonstrated that AP frequency can modulate cell secretion in adrenal chromaffin cells (Zhou and Misler, 1995; Elhamdani et al., 1998). This suggests that cells may respond to simple AP codes by releasing more transmitter at higher AP frequencies. A more complex code may contain bursts of APs, which are common in most types of neurons. It is not yet clear whether other parameters of AP bursts can also modulate secretion.

To address the quantitative relationship between AP code and secretion in a single neuron, real-time measurement of cell secretion is needed. Several methods have been developed to monitor secretion, including membrane capacitance measurements (Lindau and Neher, 1988; Gillis, 1995), electrochemical amper-

\footnotetext{
Received Sept. 29, 2003; revised 0ct. 20, 2003; accepted 0ct. 20, 2003.

This work was supported by Major State Basic Research Program of China Grant G2000077800, the National Natural Science Foundation of China (30330210), CAS Instrument Program, and the Science and Technology Commission of Shanghai Municipality. We are grateful to Dr. Christopher Lingle (Washington University, St. Louis, M0) for his kind help during part of the experiments and for his critical comments on this manuscript. We thank also Dr. lain Bruce (Hong Kong University, Hong Kong, China) for helpful comments.

${ }^{*}$ K.D. and X.Y. contributed equally to this work.

Correspondence should be addressed to Dr. Zhuan Zhou, Institute of Neuroscience, 320 Yue-Yang Road, Shanghai 200031, China. E-mail: zzhou@ion.ac.cn.

Copyright $\odot 2003$ Society for Neuroscience $\quad 0270-6474 / 03 / 2311235-09 \$ 15.00 / 0$
}

ometry recording (Wightman et al., 1991; Chow et al., 1992; Zhou and Misler, 1995), and FM 1-43 dye imaging (Betz and Bewick, 1993). In the FM 1-43 imaging method, a dye-loaded vesicle loses its signal after discharge, preventing its usage in measuring repetitive stimulation-secretion coupling (but see Aravanis et al., 2003). Compared with amperometry recording, membrane capacitance $\left(C_{\mathrm{m}}\right)$ measurement is simple (only one electrode) and accurate (total secretion from the cell). The main problem, which prevents $C_{\mathrm{m}}$ from measuring AP-induced secretion, is that recording of APs (stimulus) and $C_{\mathrm{m}}$ (response) are in conflict for the patch clamp: AP needs current clamp, but $C_{\mathrm{m}}$ needs voltage clamp. To mimic the effect of an AP, a short step depolarization or "mock AP" (using a set of ramps to mimic AP shape) has been used as a stimulus (Chan and Smith, 2001; Stewart and Foehring, 2001). However, because the shape of a native AP is much more complex, the mock AP might introduce serious errors compared with that of real APs in AP-secretion coupling.

Neuroendocrine chromaffin cells are specialized sympathetic neurons (Martini, 2001). These cells are ball shaped and 12-15 $\mu \mathrm{m}$ in diameter, ideal for patch-clamp studies. These make chromaffin cells a model neuron to study ion channels (Fenwick et al., 1982; Artalejo et al., 1990) and stimulus-secretion coupling (Augustine and Neher, 1992; Zhou and Misler, 1995; Elhamdani et al., 1998; Chan and Smith, 2001).

In this report, $\mathrm{AP}-$ secretion coupling was studied in rat adrenal chromaffin cells (RACCs). An AP template was used to build an AP code. This allowed us to investigate the cell secretion induced by different AP codes. We found, for a given number of APs, that parameters of the AP code can strongly modulate cell secretion.

\section{Materials and Methods}

Cell preparation. Methods of rat chromaffin cell isolation and maintenance in cell cultures were as described in previous reports (Neely and 
Lingle, 1992; Herrington et al., 1995; Zhou and Misler, 1995). Currents and secretion were recorded $2-7 \mathrm{~d}$ after plating. Freshly isolated DRG neurons were obtained as described previously (Huang and Neher, 1996; Zhang and Zhou, 2002) and used 1-8 hr after preparation. We used only the small neurons (15-25 $\mu \mathrm{m}, \mathrm{C}$-type neurons) (Zhang et al., 1995) lacking detectable processes.

Electrophysiological methods. Perforated-patch recordings were performed on RACCs. Whole-cell recordings were made from DRG neurons. In perforated-patch experiments, uncompensated series resistances $\left(R_{\mathrm{s}}\right)$ were typically in the range of $8-20 \mathrm{M} \Omega$. In whole-cell experiments, uncompensated series resistances were typically 5-10 M $\Omega$. Electrophysiological data were acquired through an EPC-9 amplifier under the control of Pulse software (HEKA Elektronik, Lambrecht/Pfalz, Germany).

Cell capacitance $\left(C_{\mathrm{m}}\right)$ was estimated by the Lindau-Neher technique (Lindau and Neher, 1988; Gillis, 1995) implemented as the Sine+DC feature of the Pulse lock-in module. A $1000 \mathrm{~Hz}, 20 \mathrm{mV}$ peak amplitude sine wave was applied at a holding potential of $-80 \mathrm{mV}$, and the reversal potential of the lock-in module was set to $0 \mathrm{mV}$. $C_{\mathrm{m}}$ was averaged over a $100 \mathrm{msec}$ prestimulation segment to give a baseline. The transient "gating" capacitance artifact (Horrigan and Bookman, 1994) was negligible $50 \mathrm{msec}$ after the end of stimulation. Therefore, $C_{\mathrm{m}}$ was averaged over 50-100 msec segment after the stimulation, and then the baseline $C_{\mathrm{m}}$ value was subtracted to give $\Delta C_{\mathrm{m}}$. The current was sampled at $20 \mathrm{kHz}$ after a $2.9 \mathrm{kHz}$ low-pass filter.

For intracellular $\mathrm{Ca}^{2+}$ imaging, isolated chromaffin cells were loaded with $2 \mu \mathrm{M}$ fura- $2 \mathrm{AM}$ in the bath solution for $15 \mathrm{~min}$ at $37^{\circ} \mathrm{C}$ (Zhou and Bers, 2000). Intracellular $\mathrm{Ca}^{2+}$ concentration $\left(\left[\mathrm{Ca}^{2+}\right]_{\mathrm{i}}\right)$ was measured by dual-wavelength ratiometric fluorimetry. The fura- 2 was excited with light alternating between 340 and $380 \mathrm{~nm}$ using a monochromator-based system (T.I.L.L. Photonics, Planegg, Germany), and the resulting fluorescent signals were measured using a cold CCD. Relative change in $\left[\mathrm{Ca}^{2+}\right]_{\mathrm{i}}$ was calculated from the ratio of $F_{340} / F_{380}$, which were sampled at $1 \mathrm{~Hz}$ by fluorescence imaging of the single cell (Zhang and Zhou, 2002).

Generation of AP codes, curve fitting, and data analysis were performed using macros written in Igor (WaveMetrics, Lake Oswego, OR). The paired $t$ test was run under Sigma Plot (SPSS, Chicago, IL). Means are expressed \pm SEM. All experiments were done at room temperature $\left(22-25^{\circ} \mathrm{C}\right)$

Solutions. The standard extracellular solution contained the following (in mM): $145 \mathrm{NaCl}, 2 \mathrm{CaCl}_{2}, 1 \mathrm{MgCl}_{2}, 2.8 \mathrm{KCl}, 10 \mathrm{H}$-HEPES, and 10 glucose, $\mathrm{pH}$ 7.2. For $\mathrm{Ca}^{2+}$ influx measurements, $200 \mathrm{~nm}$ TTX was added to block the $\mathrm{Na}^{+}$current. The high-Cs ${ }^{+}$solution contained the following (in mM): $145 \mathrm{CsCl}, 8 \mathrm{NaCl}, 1 \mathrm{MgCl}_{2}$, and $10 \mathrm{H}$-HEPES, pH 7.0. Here, $\mathrm{CsCl}$ was used to block $\mathrm{K}^{+}$currents for $C_{\mathrm{m}}$ recording. The high- $\mathrm{K}^{+}$ solution contained the following (in $\mathrm{mM}$ ): $145 \mathrm{KCl}, 8 \mathrm{NaCl}, 1 \mathrm{MgCl}_{2}$, and $10 \mathrm{H}$-HEPES, pH 7.0. A stock solution of Nystatin ( $125 \mathrm{mg} / \mathrm{ml}$ in DMSO) was prepared and kept frozen in the dark at $-20^{\circ} \mathrm{C}$. For perforated-patch recording, the Nystatin stock was added to the pipette solution (final concentration of Nystatin, $0.25 \mathrm{mg} / \mathrm{ml}$, according to the modified method of Zhou and Neher, 1993). For whole-cell recording, Mg-ATP was added to the pipette solution (final concentration of Mg-ATP, $4 \mathrm{mM}$ ).

Fura-2 AM at $50 \mu \mathrm{g}$ was added to $50 \mu \mathrm{l}$ of Pluronic F-127 $(12.5 \mathrm{mg} / \mathrm{ml})$ to yield a stock solution of $1 \mathrm{~mm}$ fura-2 AM. For fluorescence experiments, $1 \mu \mathrm{l}$ of fura- $2 \mathrm{AM}$ stock was added into $500 \mu \mathrm{l}$ of standard extracellular solution to get the final incubation solution. fura-2 AM was from Molecular Probes (Eugene, OR). All other chemicals were from Sigma (St. Louis, MO).

Cell-filtering effects in cells stimulated with AP waveforms. We used prerecorded real AP waveforms (APWs) as stimulus templates for the $\mathrm{AP}-$ secretion coupling under voltage clamp. According to the equivalent circuit for the whole-cell configuration, the applied voltage arrives at the cell membrane via the access resistance $(8-20 \mathrm{M} \Omega$ in this study) and membrane capacitance (5-10 pF) in chromaffin cells. Theoretically, this gives a delay of $\sim 100 \mu \mathrm{sec}$ (Marty and Neher, 1995), which is negligible even for most voltage-gated channels. For the study of AP-induced $C_{\mathrm{m}}$ signals, it is very important that the cell membrane "sees" an intact AP waveform under the voltage-clamp condition. To confirm this, we did two-electrode patch-clamping experiments on the somata of single DRG neurons. For technical reasons, such two-electrode patch clamping could
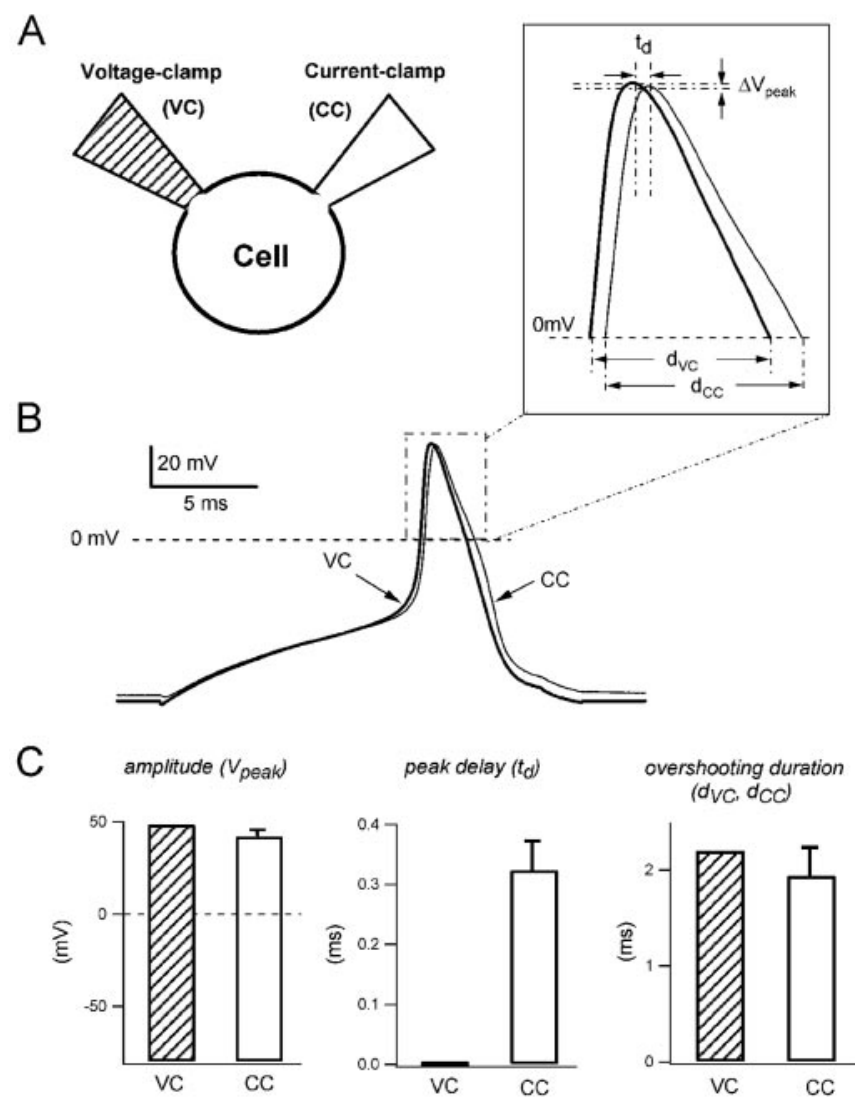

Figure 1. In the whole-cell configuration, distortion of the AP waveform by pipette cell filtering is minor in the soma of a small cell. $A$, One after another, two giga seals and two whole-cell recordings were obtained from the soma of a single DRG neuron. One electrode was in voltage-clamp mode (VC, left pipette) and the other was in current-clamp mode (CC, right pipette). An APW was applied to the cell through the patch pipette under voltage-clamp mode. Cell membrane potential was recorded from the other pipette under current-clamp mode. $B, A$ typical APW, prerecorded from a RACC, was applied to the DRG neuron. The real APW (thick line) applied via the voltage-clamp electrode (access resistance $R_{\mathrm{s}}=6.5 \mathrm{M} \Omega$ ) and the APW recorded via the current-clamp electrode (thin line; $R_{\mathrm{s}}=17 \mathrm{M} \Omega$ ) were aligned to reveal small differences in AP shape. The overshoot is expanded in the inset. Differences in AP amplitude $\left(\Delta V_{\text {peak }}\right)$, delay of the AP peak $\left(t_{\mathrm{d}}\right)$, and the overshoot durations $\left(d_{\mathrm{vc}}, d_{\mathrm{CC}}\right)$ were measured. The diameter of this neuron was $\sim 25 \mu \mathrm{m}$ with a cell capacitance of $25 \mathrm{pF}$. C, Statistics of the parameters measured in the inset in $B$. Comparing voltage clamp with current clamp, there are changes in AP amplitude $V_{\text {peak }}\left(49 \mathrm{vs} 42 \pm 4 \mathrm{mV}\right.$ ), peak time delay $\left(t_{\mathrm{d}}=0.32 \pm 0.05 \mathrm{msec}\right.$ ), and AP duration ( 2.2 vs $1.9 \pm 0.3 \mathrm{msec}$ ). These data were from four DRG neurons: $C_{\mathrm{m}}=25,18,27$, and $28 \mathrm{pF}$; voltage $\operatorname{clamp} R_{\mathrm{s}}=6.5,6.2,8.7$, and $8.9 \mathrm{M} \Omega$; and current clamp $R_{\mathrm{s}}=17,18,28$, and $11 \mathrm{M} \Omega$.

not be achieved in single chromaffin cells (the first patch seal was always lost during the process of the second pipette patching). Because the purpose was to examine the filter effect by the cell, it is reasonable to assume that the electric properties of the two types of cells are similar (except that the DRG has a larger capacitance). Because a larger $C_{\mathrm{m}}$ causes a larger distortion, the APW distortion seen in chromaffin cells should be smaller than that seen in DRG neurons. Thus, it is safe to use DRG neurons to test for APW distortion in chromaffin cells.

As shown in Figure 1, two whole-cell patches were achieved on the soma of a DRG neuron. One patch was under voltage clamp, whereas the second pipette at the other site on the cell was under current clamp. An APW prerecorded from a chromaffin cell was applied to the cell through the patch pipette under voltage clamp. The membrane voltage seen by the neuron was recorded by the second pipette under current clamp. As shown in Figure $1 B$, the only visible difference between the input (real APW) and the output (cell-filtered APW) was a $324 \pm 49 \mu$ sec delay in the current-clamp recording. The delay is slightly longer than the theoretical prediction: $R_{\mathrm{s}}{ }^{*} C_{\mathrm{m}}=7.5 \mathrm{M} \Omega * 30 \mathrm{pF}=225 \mu \mathrm{sec}$ in this cell. Because the chromaffin cell has a smaller capacitance, given $R_{\mathrm{s}}=14 \mathrm{M} \Omega$ 
and $C_{\mathrm{m}}=7.5 \mathrm{pF}$, we predict that the APW delay should be $\sim 105 \mu \mathrm{sec}$. As shown in Figure 1, other distortions (including amplitude and overshooting duration) of the APW were negligible. Thus, from these data, the patch-clamped RACCs should see nearly real AP waveforms with good fidelity.

\section{Results}

Sensitivity of ion channels to changes of APW shape

Currently, $C_{\mathrm{m}}$ can only be measured under voltage clamp. To apply membrane $C_{\mathrm{m}}$ measurement in AP-induced cell secretion, both current clamp (for APs) and voltage clamp (for $C_{\mathrm{m}}$ ) are needed. However, the transfer between voltage clamp and current clamp takes time. Thus, currently no amplifier can monitor real AP-induced secretion by $C_{\mathrm{m}}$ measurement. To avoid using current clamp, the cell is stimulated by a short step pulse or by a mock AP, which consists of several ramps, but a mock AP cannot mimic a real AP precisely. Thus, it is necessary to examine how sensitive the ion channels are to changes in the AP shape. The experiments to test the sensitivities of voltage-gated $\mathrm{Na}^{+}, \mathrm{K}^{+}$, and $\mathrm{Ca}^{2+}$ channels are shown in Figure 2. A typical APW was imitated by three ramps. Whereas the first ramp was a slow "foot," the second and third ramps generated the rapidly rising phase ( 0.9 msec duration) and the decay phase ( 4 msec duration), respectively. The peak of fast inactivating inward current was measured as peak of $\mathrm{Na}^{+}$current. The $\mathrm{Ca}^{2+}$ influx was measured by the integral of $\mathrm{Ca}^{2+}$ current. In Figure $2 A$, the duration of the second (rising) ramp was changed from 0.4 to $1.4 \mathrm{msec}$ in 0.5 msec steps (Fig. 2A2). The $\mathrm{Na}^{+}$currents (the fast inactivating inward currents in Fig. 2A1) and the $\mathrm{Ca}^{2+}$ currents (Fig. 2A3) induced by the mock AP were recorded. Relative to the intermediate ramp duration, whereas $\mathrm{Ca}^{2+}$ currents were not sensitive to the slope change in the rising phase (Fig. 2 B2), the $\mathrm{Na}^{+}$current was altered dramatically by a factor of 2 (Fig. 2B1). The $\mathrm{K}^{+}$ currents were altered as well (part of the tail currents in Fig. 2A1). The duration of the third ramp of negative slope was changed from 2 to $6 \mathrm{msec}$ in $2 \mathrm{msec}$ steps (Fig. 2C2). The $\mathrm{Na}^{+}, \mathrm{K}^{+}$(Fig. 2C1), and $\mathrm{Ca}^{2+}$ currents (Fig. 2C3) induced by the mock AP were recorded. Whereas the $\mathrm{Na}^{+}$current was not sensitive to the slope change in the decay phase, the net ion flux during the tail currents (mixing currents from $\mathrm{Na}^{+}, \mathrm{K}^{+}$, and $\mathrm{Ca}^{2+}$ channels) was altered dramatically, by fourfold (Fig. 2D1). These tail currents in Figure 2, $B 1$ and $D 1$, were reproducible, regardless of whether the ramp slopes were changed either from 2 to $6 \mathrm{msec}$ or from 6 to $2 \mathrm{msec}$. The $\mathrm{Ca}^{2+}$ influx, measured by the integral of $\mathrm{Ca}^{2+}$ currents shown in Figure 2C3, was significantly altered by $35 \pm 4 \%$ (decrease) and $28 \pm 5 \%$ (increase) compared with current at intermediate ramp duration (Fig. 2D2). These experiments suggest that voltage-gated ion channels are very sensitive to minor changes in AP shape. Thus, compared with a real AP, a step pulse or mock AP may cause large differences in currents and secretion. In contrast, an AP template should be a more physiological stimulus, because it was prerecorded from a typical RACC. For a given cell, stimulation by the reconstituted AP code under whole-cell voltage clamp is similar to that of field stimulation applied to the cell under current clamp. Together, it is better to use a real AP (not a mock AP) for the quantitative study of AP-secretion coupling.

\section{AP code and cell secretion monitored by $C_{\mathrm{m}}$ measurement}

Because voltage-gated currents are highly sensitive to the AP shape (Fig. 2), the mock AP, which cannot match the AP shape precisely, could cause unpredictable changes in stimulus-secretion coupling. Thus, we developed a method for AP-induced
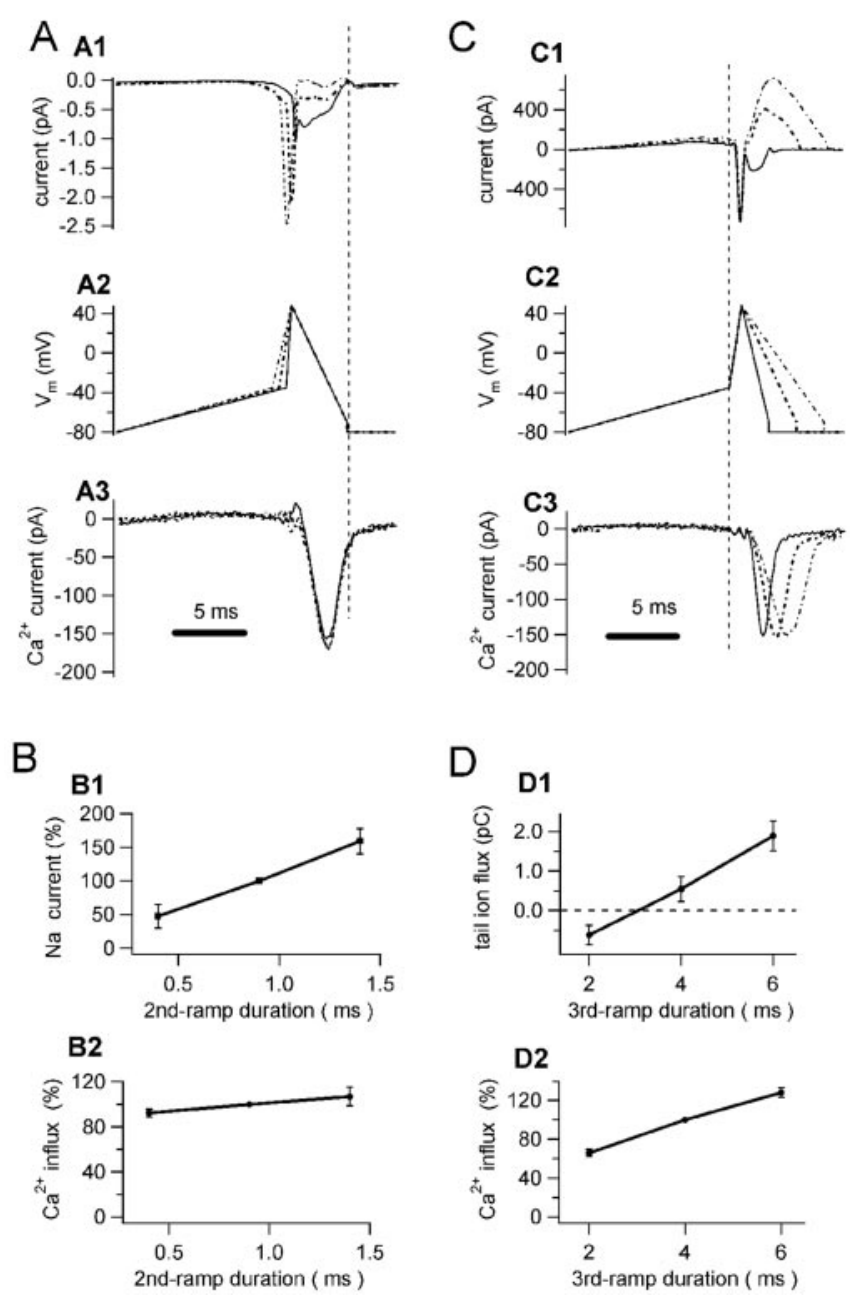

Figure 2. Voltage-sensitive channels are sensitive to slight changes in the slope of a mock AP. A, An AP waveform was simulated by three ramps as start potential, end potential, and duration as follows, respectively: $-80 \mathrm{mV},-35 \mathrm{mV}, 11.7 \mathrm{msec} ;-35 \mathrm{mV}, 48 \mathrm{mV}, 0.9 \mathrm{msec}$; and $48 \mathrm{mV},-70 \mathrm{mV}, 4 \mathrm{msec}$. To test the slope sensitivity, the second ramp duration ( $0.9 \mathrm{msec})$ was changed by $\pm 0.5 \mathrm{msec}(A 2)$. The corresponding currents induced by these three mock APs were recorded in either physiological solution (high- $\mathrm{NaCl}$ bath and high- $\mathrm{KCl}$ pipette for $\mathrm{Na}{ }^{+}$ currents; A1) or solution for $\mathrm{Ca}^{2+}$ currents (200 nM TTX in bath and high-CsCl pipette; A3). All traces in $A 1$ were from one cell. All traces in $A 3$ were from another cell. $B$, With increased ramp duration, the fast inward $\mathrm{Na}^{+}$current changed by $48 \pm 17$ and $159 \pm 19 \%$ ( 5 cells; B1). The tail currents in $A 1$, induced by the third ramp of the mock $A P$, were altered as well, but the mock AP-induced $\mathrm{Ca}^{2+}$ influx was not sensitive to this slope change ( 6 cells; $B 2$ ). C, To test the slope sensitivity of the tail ramp, the third ramp duration ( $4 \mathrm{msec}$ ) was changed by $\pm 2 \mathrm{msec}(C 2)$. The corresponding currents by these three mock APs were recorded in either physiological solution (C1) or solution for $\mathrm{Ca}^{2+}$ currents (C3). All traces in C1 were from one cell. All traces in C 3 were from another cell. $D$, With increased ramp duration, the tail ion fluxes-tail currents changed from negative (influx) $-618 \pm 243$ to $548 \pm 319$ and $1889 \pm 383 \mathrm{fC}$, respectively (6 cells; D1). As a component of the tail ion flux, the $\mathrm{Ca}^{2+}$ influx also changed by $66 \pm 4$ and $128 \pm 5 \%$, respectively (6 cells; D2).

secretion by using real APW as the basic stimulus unit under voltage-clamp conditions.

A single APW template was prerecorded in an RACC under current-clamp mode (Fig. $3 A$ ). An AP train with defined time intervals between individual APs is called an AP code, defined with the general "code function" $F(n, m, f, d)$, where the four coding parameters $(n, m, f, d)$ are defined as follows (Fig. $3 C)$. A series of consecutive APs is defined as a "burst": $n$ is the number of APs in a burst, $m$ is the number of bursts in the whole AP pattern, $f$ is the frequency of APs in a burst, and $d$ is the interval 
A

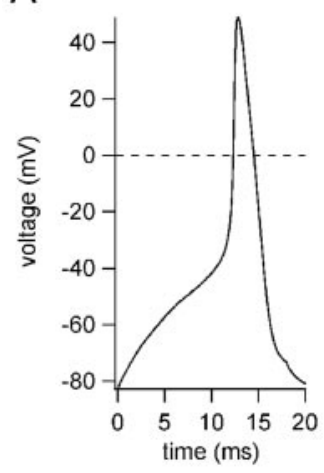

B

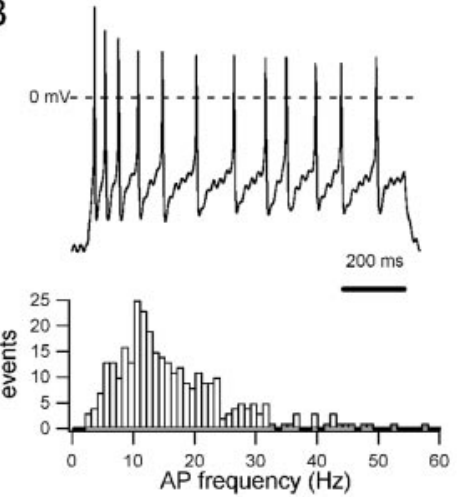

C

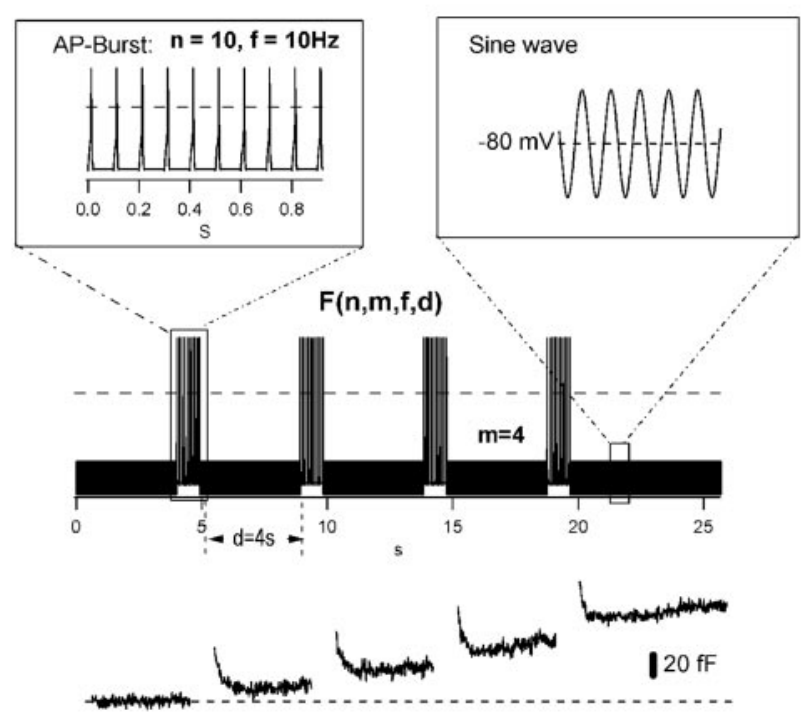

Figure 3. Defining protocols for measuring secretion in conjunction with stimulation by complex patterns of naturally occurring AP waveforms. $A$, Example of an AP elicited in an RACC during constant current injection (20 pA with a holding current of $-10 \mathrm{pA}$ ). B, Sustained current injection results in repetitive firing in many RACCs. Bottom, The instantaneous frequency for each pair of APs in such bursts is plotted for a set of 20 cells. C, A prerecorded AP (as in $A$ ) was used to construct burst patterns as defined in Results. Sequences of AP waveforms were linked to the $1000 \mathrm{~Hz}$ sine wave illustrated on the right, and the precise timing between sine wave application and AP waveforms was defined as described in Materials and Methods. Bottom, An example of four bursts of APs, each containing $10 \mathrm{APs}$ occurring at $10 \mathrm{~Hz}$, which were used to stimulate a RACC resulting in the $C_{m}$ trace shown below. With perforated-patch recording, a decrement in $C_{m}$ indicative of endocytosis was typically observed after stimulation .

between two adjacent bursts (when $m=1, d$ has no meaning). Clearly, this equation defines only a simple kind of AP code. However, a more complex AP code can be built with several simple AP codes from this equation.

A prerecorded AP from a current-clamp recording in an RACC (Fig. 3B) was used as the elementary APW template and programmed with Igor software. This APW template (Fig. 3A) was used to produce an AP code $F(n, m, f, d)$ with a laboratorymade macro program in Igor. A macro procedure from HEKA Elektronik was used to transfer the protocol to a file template of Pulse software. To get defined time intervals between APs and AP bursts, we made the whole $F(n, m, f, d)$ as a single AP code template file for Pulse. As required by $C_{\mathrm{m}}$ measurement, a sine wave of $40 \mathrm{mV}$ (peak-to-peak) and $1 \mathrm{kHz}$ was inserted throughout the protocol, except during AP bursts. Using this AP- $C_{\mathrm{m}}$ protocol, the AP-induced $C_{\mathrm{m}}$ signals are recorded when $\mathrm{AP}$ code $F(10,4,10$ $\mathrm{Hz}, 5 \mathrm{sec}$ ) was applied to an RACC (Fig. 3C).
A

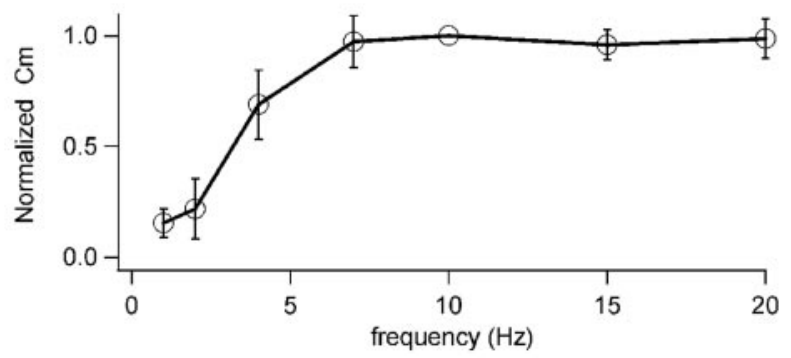

B
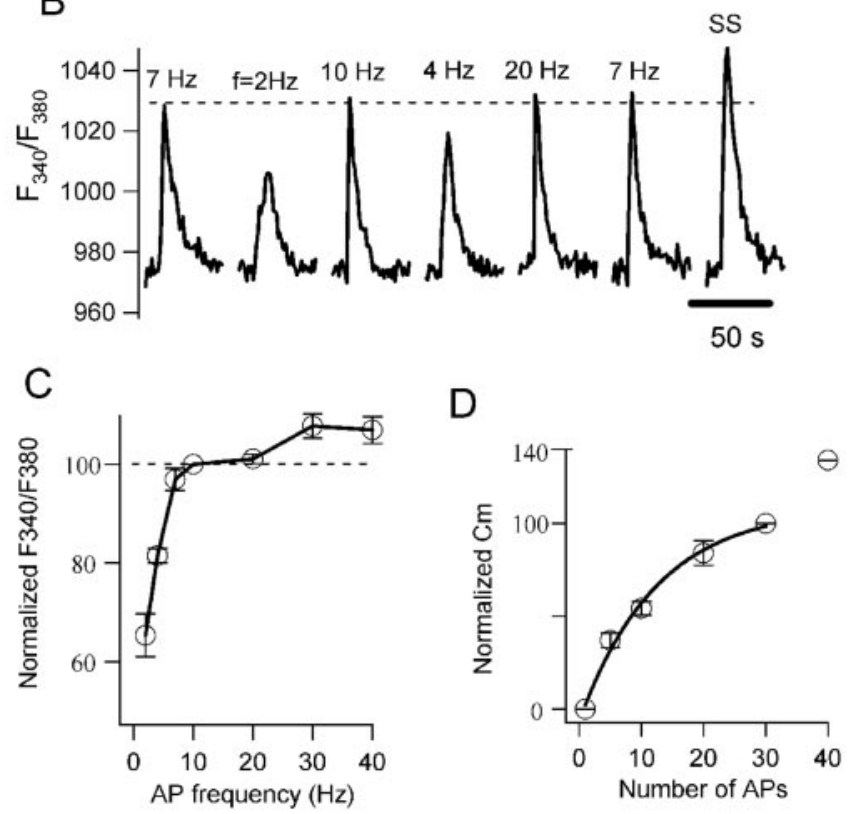

Figure 4. Influence of $f$, action potential frequency, and $n$, number of action potentials in a burst, on secretion. $A$, Effect of frequency on secretion. Twenty APs were applied to a cell at different frequencies. Secretion was normalized to that evoked by a $10 \mathrm{~Hz}$ stimulus (at $10 \mathrm{~Hz}$, $\Delta C_{\mathrm{m}}=28 \pm 3 \mathrm{fF}$ ). Normalized $\Delta C_{\mathrm{m}}$ was plotted for a set of seven cells and shows that secretion increased as fincreased from 1 to $7 \mathrm{~Hz}$. Additional increases in frequency did not evoke more secretion. For $f \geq 7 \mathrm{~Hz}$, the interval between adjacent APs was too short to measure $C_{m}$, so it was measured after the 20 APs. For $f=1,2$, and $4 \mathrm{~Hz}$, to eliminate possible effects of endocytosis during the intervals between adjacent APs, total secretion $\left(C_{m}\right)$ was taken as the sum of the 20 individual AP-induced $C_{\mathrm{m}}$. $B$, Effect of frequency on $\left[\mathrm{Ca}^{2+}\right]_{\mathrm{i}}$. Twenty APs were applied to cells at different frequencies. $\left[\mathrm{Ca}^{2+}\right]_{i}$ increased when $f$ increased from 2 to $7 \mathrm{~Hz}$. However, the increase in $\left[\mathrm{Ca}^{2+}\right]_{i}$ saturated at frequencies higher than $7 \mathrm{~Hz}$. The $\left[\mathrm{Ca}^{2+}\right]_{i}$ saturation at $f \geq 7 \mathrm{~Hz}$ was not attributable to dye saturation, because stronger stimulation (40 APs applied at $10 \mathrm{~Hz}$ in a single burst; SS) could increase $\left[\mathrm{Ca}^{2+}\right]_{\mathrm{i}}$ further. $C$, Statistics of $B .\left[\mathrm{Ca}^{2+}\right]_{i}$ is nearly saturated for $f \geq 7 \mathrm{~Hz}$ (6 cells). $D$, Effect on secretion of bursts of different numbers of APs, all applied at $10 \mathrm{~Hz}$. For $n=30, \Delta C_{\mathrm{m}}=28 \pm 3 \mathrm{fF}$. The relationship between total $\Delta C_{\mathrm{m}}$ and the number of APs is plotted for eight cells.

\section{Frequency dependence of secretion (the $f$ effect)}

Chromaffin cells fire APs during stimulation from cholinergic neurons and release catecholamine (Kidokoro and Ritchie, 1980). To test the range of AP frequency in native firing, a current step ( $1 \mathrm{sec}$, to $20 \mathrm{pA}$ ) was injected to an RACC to evoke APs. By measuring the interval between two adjacent APs, frequency was calculated. The distribution of AP frequencies is shown in Figure $3 B$. Because $80 \%$ of firing occurs at frequencies lower than $20 \mathrm{~Hz}$, only frequencies below that value were used in this work. Using amperometric measurements, Zhou and Misler (1995) reported that, with a given $\mathrm{AP}$ number, an increase of AP frequency from 1 to $4 \mathrm{~Hz}$ increases the amount of secretion by twofold in RACCs. As shown in Figure 4A, using membrane capacitance measure- 
ments, we confirmed that secretion increased when AP frequency $f$ was increased from 1 to $7 \mathrm{~Hz}$. However, we found no further increase at higher frequencies. To investigate the $f$ saturation, the intracellular calcium concentration $\left(\left[\mathrm{Ca}^{2+}\right]_{\mathrm{i}}\right)$ was monitored by combined patch-clamp and fura-2 fluorescence. In the calcium imaging experiments (Fig. $4 B)$, a given number $(n=20)$ of APs was applied to a cell in one burst but at different frequencies. The peak $\left[\mathrm{Ca}^{2+}\right]_{\mathrm{i}}$ change induced by the AP trains increased from $f=$ $2 \mathrm{~Hz}$ to $f=7 \mathrm{~Hz}$ and nearly saturated after $f \geq 7 \mathrm{~Hz}$ (Fig. 4C). This result was consistent with the secretion result (Fig. $4 A$ ). The saturation of the $\left[\mathrm{Ca}^{2+}\right]_{\mathrm{i}}$ change was not attributable to saturation of the fura- 2 dye, because $\left[\mathrm{Ca}^{2+}\right]_{\mathrm{i}}$ could be further increased with a stronger pulse stimulus. During stimulation with APs, calcium ions passed through calcium channels and accumulated in the cytoplasm. At lower frequencies such as 1 or $2 \mathrm{~Hz}$, the accumulation was weak because of the activity of $\mathrm{Ca}^{2+}$ clearance mechanisms. Only the vesicles near the $\mathrm{Ca}^{2+}$ channel could be released. At higher frequencies, the residual $\mathrm{Ca}^{2+}$ could accumulate. This allowed the release of vesicles far from the calcium channels. When frequency was higher than $7 \mathrm{~Hz}$, there was no further accumulation, probably because the clearance effect is negligible during the short interval between two adjacent APs. The similar $f$ effects for both secretion and $\left[\mathrm{Ca}^{2+}\right]_{\mathrm{i}}$, particularly the similar saturation of the $f$ effect at $f>7 \mathrm{~Hz}$, is consistent with the hypothesis that AP-induced secretion is exclusively $\mathrm{Ca}^{2+}$ dependent in chromaffin cells (Augustine and Neher, 1992; Zhang and Zhou, 2002).

\section{The relationship between secretion and number of APs ( $n$ effect)}

Because the effect of frequency saturated when $f$ was higher than $7 \mathrm{~Hz}$, an AP burst of $10 \mathrm{~Hz}$ was used in the following experiment to investigate the effect of another coding parameter, " $n$," on RACC. As shown in Figure 4D, the amount of secretion increased when the number of APs increased, but the relationship between secretion and $n$ was not linear. It can be fitted by a singleexponential function. The rundown of AP efficiency could be for two possible reasons. One is that the $\mathrm{Ca}^{2+}$ influx evoked by each AP decreases during stimulation. In the latter part of this paper, the rundown of $\mathrm{Ca}^{2+}$ influx is described (Fig. $5 C$ ). This suggests that rundown of $\mathrm{Ca}^{2+}$ influx might participate in this process. Another possible reason is a limit defined by the size of the readily releasable pool (RRP) of vesicles. In this case, the calcium ions entering with later APs have less chance to trigger release of vesicles (see Discussion). Note that, at $n=40 \mathrm{APs}, C_{\mathrm{m}}$ was significantly larger than the predicted plot value ( $p<0.01$; eight cells). This is probably because a facilitation of secretion starts after 30 APs at $f=10 \mathrm{~Hz}$ (Zhou and Misler, 1995).

\section{Parameters of inter-AP bursts modulated secretion dramatically ( $m$ and $d$ effects)}

Parameters $m$ and $d$ define the inter-AP bursts of an AP code. To test the effect of number of bursts or $m$, the other parameters were set as $n=40 / m, f=10 \mathrm{~Hz}$, and $d=4 \mathrm{sec}$. The total number of APs in the AP code was fixed at $40=n^{*} m$. The result of $m=1$ versus $m=4$ is shown in Figure $5 A$. The left and right panels show control and recovery of $C_{\mathrm{m}}$ induced by $F(40,1,10 \mathrm{~Hz}, 4 \mathrm{sec})$. The middle panel shows the $C_{\mathrm{m}}$ trace induced by $F(10,4,10 \mathrm{~Hz}, 4 \mathrm{sec})$. These results are summarized in Figure $5 D$. Although the total number of APs and AP frequency were fixed $(n * m=40 ; f=10$ $\mathrm{Hz})$, the four-burst AP code evoked secretion $2.2 \pm 0.1$ times greater than that caused by a single burst $(p<0.01)$. The $\left[\mathrm{Ca}^{2+}\right]_{\mathrm{i}}$ signals responsible for these differences in secretion are illus-
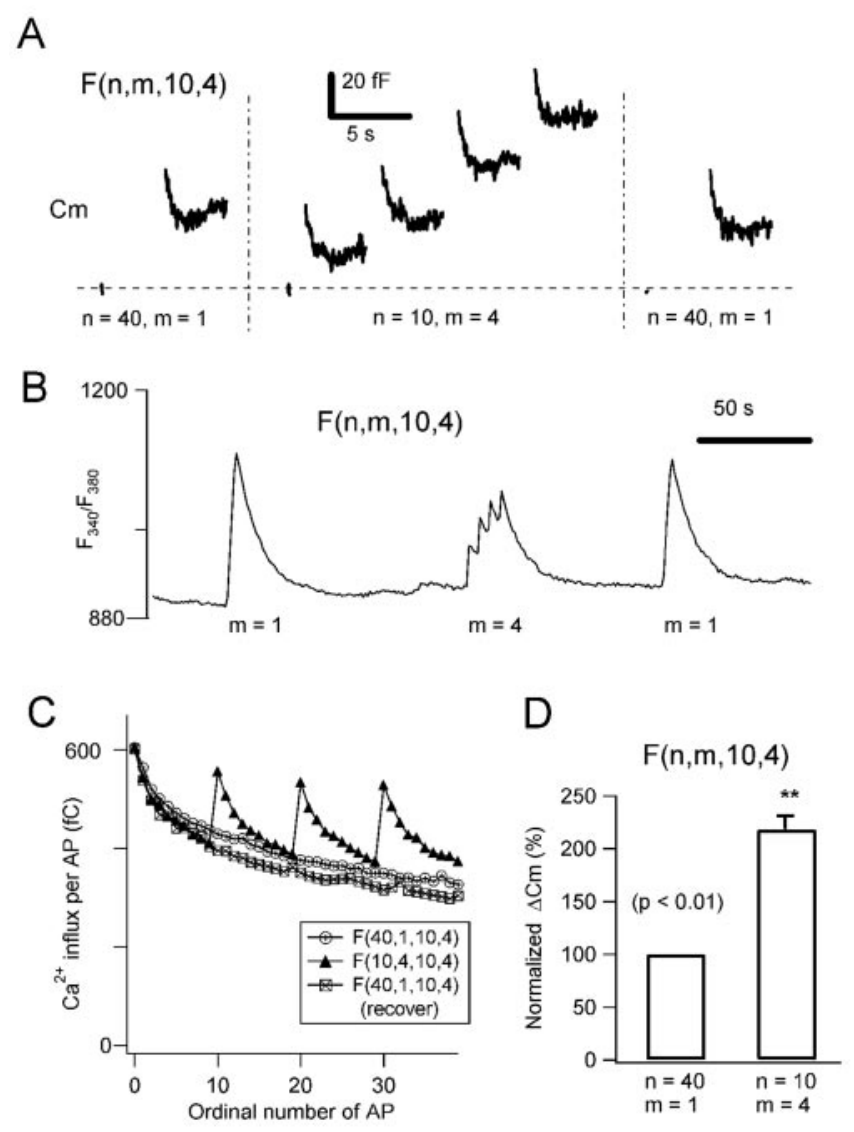

Figure 5. Modulation of secretion and $\left[\mathrm{Ca}^{2+}\right]_{\mathrm{i}}$ by number of AP bursts, $m$. $A$, Secretion induced by one- or four-burst stimuli. Secretion was measured as $\Delta C_{m}$ (change of $C_{m}$ after AP code stimulation). The apparent $\Delta C_{m}$ was twofold larger when the same total number of APs ( $n=40$ ) was presented in four bursts separated by $4 \mathrm{sec}$. To compare the AP code-induced secretion signals, segments of the $C_{m}$ before stimulation were placed on the same baseline. The $\Delta C_{\mathrm{m}}$ evoked by each burst was added to obtain total secretion evoked by the protocol. $B$, Effect of the two protocols in $A$ on changes in cytosolic $\left[\mathrm{Ca}^{2+}\right]_{\mathrm{j}}$. In this case, the single burst of $40 \mathrm{APs}$ resulted in a larger apparent increase in peak $\left[\mathrm{Ca}^{2+}\right]_{\mathrm{i}}$. Similar results were obtained in 17 cells. $C$, The net $\mathrm{Ca}^{2+}$ influx per AP plotted for the two protocols illustrated in $A$. In one case, a continuous burst of $40 \mathrm{APs}$ was applied at $10 \mathrm{~Hz}$, or AP code $F(40,1,10 \mathrm{~Hz}, d)$. In the other, four bursts each of $10 \mathrm{APs}$ at $10 \mathrm{~Hz}$ were applied at an interburst interval of $4 \mathrm{sec}$, or AP code $F(10,4$, $10 \mathrm{~Hz}, 4 \mathrm{sec}$ ). For continuous stimulation, a gradual decrease in net $\mathrm{Ca}^{2+}$ influx was observed. In the protocol with $m=4$, net $\mathrm{Ca}^{2+}$ influx recovered between bursts. Thus, 40 APs applied as four separate bursts elicited more $\mathrm{Ca}^{2+}$ influx than $40 \mathrm{APs}$ applied at $m=1$. D, The statistical results of $m=1$ versus $m=4$ for 12 cells. For $m=1$, total $\Delta C_{m}=34 \pm 9$ fF. The four-burst stimulus evoked $2.2 \pm 0.1$ times more secretion $(p<0.01)$.

trated in Figure 5B. The single-burst stimulus evoked a much higher but narrower $\mathrm{Ca}^{2+}$ spike than the four-burst stimulus. A stronger stimulus (80 APs applied at $20 \mathrm{~Hz}$ in a single burst) was applied at the end of the experiment to make sure that there was no saturation of the dye. In the $\left[\mathrm{Ca}^{2+}\right]_{i}$ spike evoked by the four-burst stimulus, the peaks induced by each burst could be distinguished. Although these peaks were smaller than the maximum $\left[\mathrm{Ca}^{2+}\right]_{\mathrm{i}}$, the AP code of $m=4$ evoked more secretion than the AP code of $m=1$. The $m$ effect was further confirmed by $m=$ 2 versus $m=4$. To make error induced by endocytosis minimal, the total stimulus duration was fixed. The protocols $F(10,4,10$ $\mathrm{Hz}, 1.36 \mathrm{sec})$ and $F(20,2,10 \mathrm{~Hz}, 4 \mathrm{sec})$ were applied. The secretion evoked by $F(10,4,10 \mathrm{~Hz}, 1.36 \mathrm{sec})$ was $1.3 \pm 0.1$ times larger than that evoked by $F(20,2,10 \mathrm{~Hz}, 4 \mathrm{sec}$ ) (data not shown; 12 cells).

As shown in Figure $5 C$, the calcium current caused by each AP 

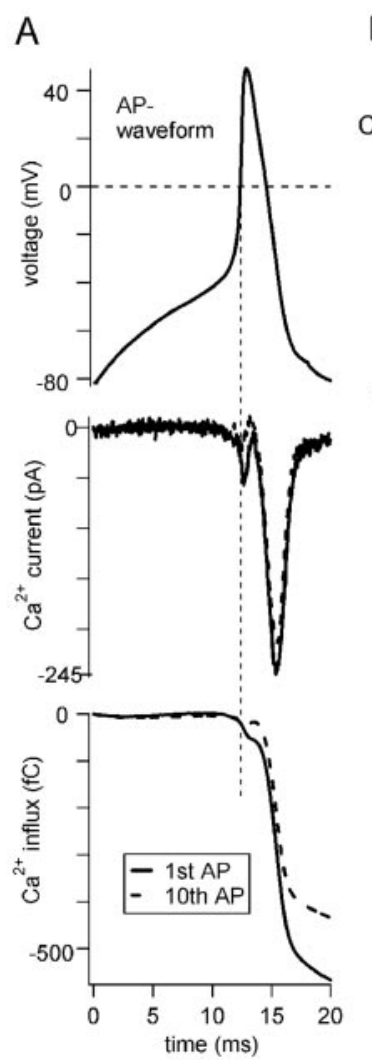

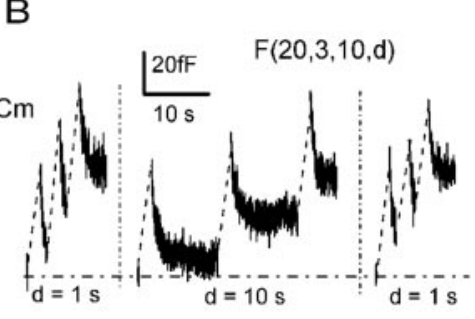

C
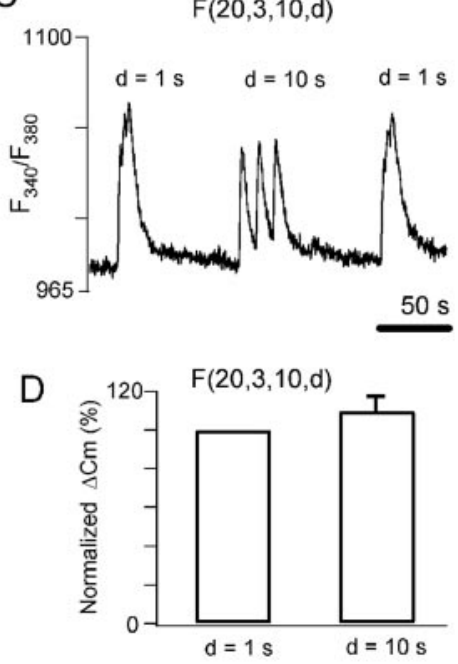

Figure 6. Effects of interval time $d$ on $\left[\mathrm{Ca}^{2+}\right]_{\mathrm{i}}$ and secretion. $A$, To record $\mathrm{Ca}^{2+}$ currents, $\mathrm{Na}^{+}$and $\mathrm{K}^{+}$currents were blocked by TTX in the bath and high $\mathrm{Cs}^{+}$in the patch pipette. The AP waveform shown in the top elicited the $\mathrm{Ca}^{2+}$ currents (1st and l0th AP in a burst) shown in the middle. The $\mathrm{Ca}^{2+}$ current was integrated to determine the total amount of $\mathrm{Ca}^{2+}$ influx (bottom). $B$, Effects of stimuli in which the interval time between bursts, $d$, was either 1 or 10 sec. $\Delta C_{m}$ in both cases was similar as summarized below. $C$, Effect of protocols with different $d$ (1 or $10 \mathrm{sec}$ ) on changes in cytosolic $\left[\mathrm{Ca}^{2+}\right]_{\mathrm{i}}$. The protocol with the shorter interval caused a higher peak of cytosolic $\left[\mathrm{Ca}^{2+}\right]_{\mathrm{i}}$, even in the absence of more secretion (Fig. 5). Similar results were obtained in six cells. $D$, The statistical result of $d=1$ sec versus $d=10$ sec for 15 cells. For $d=1 \mathrm{sec}$, total $\Delta C_{\mathrm{m}}=65 \pm 9 \mathrm{fF}$. The paired $t$ test showed no difference.

was counted and plotted against its ordinal number. A clear rundown of calcium current was observed (Fig. 6A). During the interburst interval, the $\mathrm{Ca}^{2+}$ channels recovered, so that the fourburst stimulus could induce more $\mathrm{Ca}^{2+}$ influx. On the other hand, it is likely that the RRP would also recover during the interval between bursts. Thus, both of these factors might contribute to the larger response elicited by the four-burst protocol. This $m$ effect could have important physiological consequences (see Discussion).

To monitor pure calcium current and Ca influx during a single AP stimulus, TTX was added to the bath solution to block the sodium channels (Fig. 6A). With a given number of APs (i.e., $n^{*}$ $m$ ) and given stimulation time (time between first and last APs), $d$ is a parameter depending on $m$. Thus, the $m$ effect shown in Figure $5 \mathrm{~A}$ should be considered as the combined effects of $m$ and $d$. However, if the stimulation time is not fixed, $d$ is independent of the other three coding parameters. When $d$ is shortened to zero, several bursts $(m>1)$ will form one continuous burst $(m=$ 1 ), which is treated in Figure $5 A$ as the $m$ effect. In the following, we only consider the situation in which $d$ was longer than $1 \mathrm{sec}$. To test the $d$ effect, the other parameters were set as $n=20, m=$ 3 , and $f=10 \mathrm{~Hz}$. As shown in Figure 6, $B$ and $C$, two AP codes of $d=1 \mathrm{sec}$ and $d=10 \mathrm{sec}$ produced a similar $\Delta C_{\mathrm{m}}$ but different $\left[\mathrm{Ca}^{2+}\right]_{\mathrm{i}}$ (Fig. $6 D, 15$ cells). The AP code of $d=1 \mathrm{sec}$ caused a

A

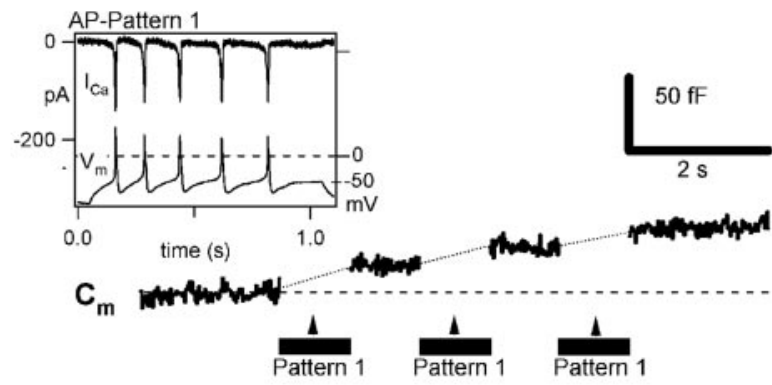

B

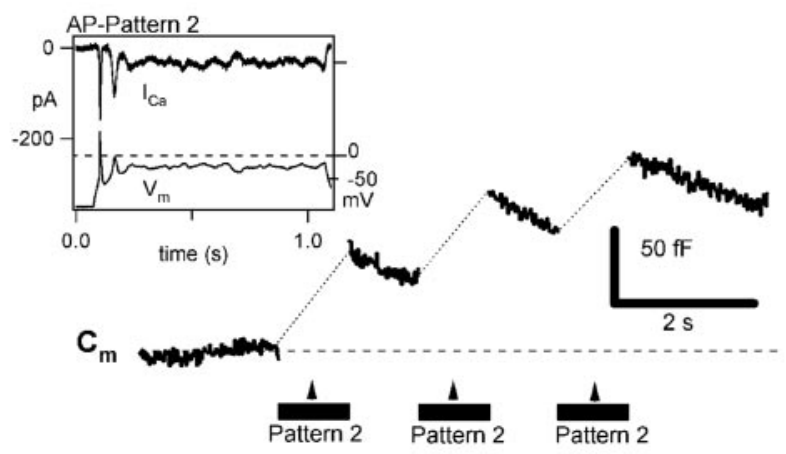

C

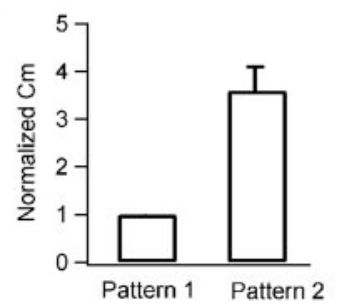

D

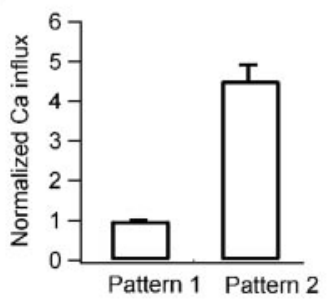

Figure 7. Modulation of secretion by more complex natural action potential waveforms. $A$, $B$, The bottom traces of the insets show two types of complex natural AP burst waveforms (patterns 1 and 2) observed in RACCs during 1 sec of $10 \mathrm{pA}$ current injection. The top traces of each inset show the $\mathrm{Ca}^{2+}$ currents evoked by the application of such AP burst stimuli. In $A$, the AP burst of pattern 1 was used to build the AP code ( $m=3, d=1 \mathrm{sec}$ ), which was applied to the cell and induced a $C_{m}$ increase of $45 \mathrm{fF}$. In $B$, the AP burst of pattern 2 was used to build the same AP code ( $m=3, d=1 \mathrm{sec}$ ), which was also applied to the same cell of $A$ and induced a $C_{m}$ increase of $180 \mathrm{fF}$, or four times larger than the AP code using pattern 1 . C, The statistical results from six cells. Pattern 2 evoked $3.59 \pm 0.50$ times more secretion than pattern $1(p<0.01)$. For pattern 1, total $\Delta C_{\mathrm{m}}=79 \pm 22 \mathrm{fF}$. $D$, Calculated calcium influxes during the stimuli. Note that pattern 2 evoked $4.52 \pm 0.40$ times more $\mathrm{Ca}^{2+}$ influx than pattern $1(p<0.01)$.

higher but briefer $\left[\mathrm{Ca}^{2+}\right]_{\mathrm{i}}$ spike. An intrinsic limitation of $C_{\mathrm{m}}$ measurement is that $C_{\mathrm{m}}$ is the net capacitance change resulting from total exocytosis and endocytosis. A decay phase is seen after the AP-induced $C_{\mathrm{m}}$ increase. This decay is most likely attributable to membrane retrieval or endocytosis. Thus, it is possible that endocytosis may occur simultaneously with exocytosis during the $\mathrm{AP}$ burst, and the apparent $\mathrm{AP}$-induced $C_{\mathrm{m}}$ increases are probably underestimated.

\section{Effect of different types of native AP bursts}

Two typical subtypes of AP firing were encountered in cultured RACCs. Pattern 1, which accounted for $\sim 40 \%$ of RACCs, was firing with consecutive APs (Fig. 7A, inset). Pattern 2, which accounted for an additional $40 \%$ of RACCs, was firing in which one AP was followed by a prolonged plateau (Fig. $7 B$, inset). The remaining $20 \%$ had AP patterns intermediate between the two patterns. Each cell displayed a specific AP pattern in response to current injection (5-10 pA for a good seal), which was slightly 
above the threshold to generate APs. The AP pattern was relatively insensitive to injection currents of up to 10 times threshold. Using these two native bursts as templates, we built two types of AP codes with given $m$ and $d(m=3 ; d=1 \mathrm{sec})$. As shown in Figure $7, A$ and $B$, the secretion induced by the AP code of pattern 2 was much greater than that with the AP code of pattern 1 . On average, the $C_{\mathrm{m}}$ induced by pattern 2 was at least $3.6 \pm 0.5$ times greater than that by pattern 1 . This drastic difference in secretion was apparently attributable to $\mathrm{Ca}^{2+}$ influx during the long plateau of pattern 2 (Fig. $7 B$, inset, bottom trace), which was much larger than that of pattern 1 (Fig. $7 A$, inset, bottom trace). Statistically, the $\mathrm{Ca}^{2+}$ influx induced by pattern 2 was $4.5 \pm 0.4$ times larger than that of pattern 1 . This experiment demonstrated that, like reconstituted AP codes, native AP codes (not just the number of APs and duration of AP bursts) strongly modulate cell secretion in RACCs.

\section{Discussion}

In this report, we describe a capacitance method to study APinduced secretion in single RACCs. In this method, AP patterns are defined by a four-parameter code function, $F(n, m, f, d)$. Secretion evoked by stimulation with an AP code was measured by membrane capacitance $\left(C_{\mathrm{m}}\right)$ in real time. We found, in addition to AP frequency, another parameter of the AP code, that the number of AP bursts $(m)$ can effectively modulate cell secretion.

\section{A capacitance method to study AP-induced secretion}

The physiological stimuli in neurons are APs, which can be recorded by current clamp. Quantitative secretion can be recorded in real time by using the voltage-clamp method to measure $C_{\mathrm{m}}$. In the AP- $C_{m}$ method, we prerecorded a real AP or AP burst under current clamp. Then we used it as a template waveform to reconstitute a complex firing pattern (AP code). This computer generated AP code template was then applied to a cell in voltage-clamp mode. With a built-in sine wave stimulus, the secretion of the cell was recorded by the lock-in $C_{\mathrm{m}}$ measurement. This method allowed us to analyze the "AP information" contained in a given AP code, which can be "read-out" by recording the corresponding $C_{\mathrm{m}}$ of a cell.

The AP- $C_{\mathrm{m}}$ method has two drawbacks. First, the capacitance response is a mixture of exocytosis and endocytosis. Thus, the capacitance response induced by an AP code may be contaminated by endocytosis during AP stimulation. The endocytosis would cause underestimation of total secretion. Because endocytosis is coupled with exocytosis, this estimation error is larger for stronger stimulation (Neher and Zucker, 1993; Thomas et al., 1994). Second, the AP- $C_{m}$ method can only be applied to cells that can be voltage clamped. This limitation sets requirements for the shape and size of a cell (Gillis, 1995). As shown in this report, RACCs meet these conditions.

\section{Mechanisms for modulation of secretion by AP codes}

The amount of AP code-induced secretion depends on the size of the RRP and its refilling rate after depletion. In the bovine chromaffin cell, RRP size is estimated to be between 20 and $45 \mathrm{fF}$ (Gillis et al., 1996). In the rat chromaffin cell, an estimate of $34 \mathrm{fF}$ has been made (Horrigan and Bookman, 1994). The maximum recovery rate of the RRP is $0.007 \mathrm{sec}^{-1}$ (Smith et al., 1998). In our experiments, a $10 \mathrm{AP}$ burst (at $10 \mathrm{~Hz}$ ) released half of the RRP. After secretion induced by an AP code, a proportion of the released vesicles will be recycled from the cell membrane and reloaded for the next release.

Depletion of the RRP during the AP burst provides a possible mechanism for the $m$ effect: the AP code $F(10,4,10 \mathrm{~Hz}, 4 \mathrm{sec})$ $(m=4$; total APs $=40 ; f=10 \mathrm{~Hz} ; d=4 \mathrm{sec})$ evokes twice the secretion induced by the AP code $F(40,1,10 \mathrm{~Hz}, 4 \mathrm{sec})(m=1$; total APs $=40 ; f=10 \mathrm{~Hz} ; d=4 \mathrm{sec})$. For $m=1$, the long AP burst might deplete the RRP during the first 20 APs, so fewer vesicles are available for later APs. For $m=4$, the RRP could be refilled during the intervals between two shorter AP bursts, so more RRP vesicles are available for the next short AP burst of the AP code.

An alternative mechanism for the $m$ effect, as well as the $f$ effect, could be the difference in $\mathrm{Ca}^{2+}$ influx generated by two AP codes. During a burst of APs, a decreased calcium current was induced by later APs attributable to inactivation of $\mathrm{Ca}^{2+}$ channels (Fig. 5C). During the interval between two bursts, the $\mathrm{Ca}^{2+}$ currents, including T-, N-, and L-types (Hollins and Ikeda, 1996; Prakriya and Lingle, 2000), exhibited recovery. Thus, the fourburst stimulus induced more $\mathrm{Ca}^{2+}$ influx.

Finally, the large dense-core vesicles are docked at a substantial distance $(300 \mathrm{~nm}$ ) from the site of calcium influx (Zhou and Misler, 1995; Klingauf and Neher, 1997; Elhamdani et al., 1998; Mansvelder and Kits, 2000). In the presence of mobile and immobile $\mathrm{Ca}^{2+}$ buffers, the local $\mathrm{Ca}^{2+}$ concentration decays sharply along the $300 \mathrm{~nm}$ diffusion pathway (Nowycky and Pinter, 1993; Zhou and Neher, 1993). The $\mathrm{Ca}^{2+}$ concentration needs to reach a threshold level before triggering secretion (Kao and Schneider, 1986; Neher, 1998). The $\mathrm{Ca}^{2+}$ gradient determines when and where a vesicle fusion occurs. When the frequency is high, the calcium accumulation is fast enough to compete with the $\mathrm{Ca}^{2+}$ clearance system. This "gradient hypothesis" explains the $f$ effect but not the $m$ effect.

The control of $\mathrm{Ca}^{2+}$-dependent secretion by AP codes, particularly parameters $m$ and $d$, is a sum of the kinetics of $\left[\mathrm{Ca}^{2+}\right]_{i}$ and the RRP. Both $\left[\mathrm{Ca}^{2+}\right]_{\mathrm{i}}$ (influx and clearance) and the RRP (exocytosis and refilling) also depend on many positive and negative regulators. Thus, depending on the native ion channels of a neuron, the two variables of the AP codes illustrated in Figure 5 could provide four different effects: (1) $m$ positive and $d$ positive; (2) $m$ positive and $d$ negative; (3) $m$ negative and $d$ positive; and (4) $m$ negative and $d$ negative. It so happens that the behavior of the RACCs was $m$ positive and $d$ negative under the conditions of Figures 5 and 6, respectively. For example, Figure 5 shows that the RACC has effect type 2: the total secretion was dependent on $m$ with the combination $(n, f, d)$ of Figure $5 A$, although it was independent of $d$ with another combination $(n, m, f)$ of Figure $6 B$. We should emphasize that, for given total time $(T)$ of AP codes, the $d$ and $m$ are actually related by the following formula: $T=m^{*} n / f+d^{*}(m-1)$. Thus, the $d$ effect can also be considered another type of $m$ effect. This means that the $m$ effect on secretion could differ for different combinations of parameters.

\section{Physiological impact of AP code}

Using the AP- $C_{\mathrm{m}}$ method, we studied the secretory response of a cell to different AP codes. With a given number of APs, cell secretion is modulated not only by AP frequency $(f)$ but also by burst pattern ( $m$ and $d$ ). The $m$ effect is important, because it increases the ability of a neuron to process AP information. By changing parameters $(n, m, f, d)$ of the AP code, the outputsecretion of a neuron can be modulated. Interestingly, a variety of AP codes exist in different types of neurons, in same type of neurons, or even in the same neuron. Our experiments provide evidence that AP codes contain distinct types of information. This cellular coded information is an addition to structure-based synaptic plasticity [i.e., long-term potentiation (LTP)] (Otani and Ben-Ari, 1993). 
Short-term plasticity includes facilitation and depression. The $f$ effect, or secretion facilitation by higher AP frequencies, has been found not only in RACC but also in many other neurons (for review, see Zucker, 1989). However, the $m$ effect on secretion was less known. In RACC, the $m$ effect is likely a combination of facilitation (Fig. 4) (Charlton and Bittner, 1978; Zhou and Misler, 1995, their Fig. 1) and depression (during the first 30 APs in Fig. 4D) (Zucker, 1989). We believe, like the $f$ effect, the $m$ effect probably exists in most other neurons. It is possible that the $m$ effect differs among different cell types, because the final secretion depends on many factors, including the shape of a single AP, the AP code, ion channels, fusion proteins, colocalization of channels and vesicles, vesicle pools, and $\mathrm{Ca}^{2+}$ buffers. All of these factors vary among different types of cells. It is thus possible that, for an A-type cell, pattern F1 evokes more secretion than pattern F2. However, for a B-type cell, pattern F1 evokes less secretion than pattern F2. In fact, our preliminary data in DRG neurons support this prediction: the same two AP codes as those shown in Figure 5 produced a completely opposite $m$ effect (our unpublished observation). Using postsynaptic potential (PSP) as the bioassay, it was found that dividing a given number of stimuli into several groups to produce a "temporal pattern stimulation" can induce LTP more efficiently than a constant frequency stimulus train (Tsukada et al., 1994; Dobrunz and Stevens, 1999). One important advantage of the present work is that our $C_{\mathrm{m}}$ signal is exclusively attributable to presynaptic events, although the effect on LTP measured by PSPs could not exclude postsynaptic contamination (i.e., receptor desensitization). The fact that the $m$ effect of RACC using $C_{\mathrm{m}}$ assay is consistent with effect of temporal patterns of APs using PSP assay (Tsukada et al., 1994; Tsodyks and Markram, 1997; Dobrunz and Stevens, 1999) suggests that those PSP facilitation-LTPs might be dominated by a presynaptic mechanism.

Because of technical challenges, capacitance measurement cannot be applied to many cell types. However, our AP code protocol can be extended to cells beyond patch-clamping conditions. Combined with AP code stimulation, another secretion assay (i.e., EPSCs, FM 1-43 dye, or amperometry) might be used. Furthermore, the AP code stimulation protocol can even be used as extracellular field stimulation. In this way, AP codes can be applied to virtually all types of neurons in brain slices or even in in vivo recordings. It would be of great interest to study stimulussecretion coupling using AP code protocols in CNS neurons.

\section{References}

Aravanis AM, Pyle JL, Tsien RW (2003) Single synaptic vesicles fusing transiently and successively without loss of identity. Nature 423:643-647.

Artalejo CR, Ariano MA, Perlman RL, Fox AP (1990) Activation of facilitation calcium channels in chromaffin cells by D1 dopamine receptors through a cAMP/protein kinase A-dependent mechanism. Nature 348:239-242.

Augustine GJ, Neher E (1992) Calcium requirements for secretion in bovine chromaffin cells. J Physiol (Lond) 450:247-271.

Betz WJ, Bewick GS (1993) Optical monitoring of transmitter release and synaptic vesicle recycling at the frog neuromuscular junction. J Physiol (Lond) 460:287-309.

Chan SA, Smith C (2001) Physiological stimuli evoke two forms of endocytosis in bovine chromaffin cells. J Physiol (Lond) 537:871-885.

Charlton MP, Bittner GD (1978) Presynaptic potentials and facilitation of transmitter release in the squid giant synapse. J Gen Physiol 72:487-511.

Chow RH, von Ruden L, Neher E (1992) Delay in vesicle fusion revealed by electrochemical monitoring of single secretory events in adrenal chromaffin cells. Nature 356:60-63.

Dobrunz LE, Stevens CF (1999) Response of hippocampal synapses to natural stimulation patterns. Neuron 22:157-166.
Elhamdani A, Zhou Z, Artalejo CR (1998) Timing of dense-core vesicle exocytosis depends on the facilitation L-type $\mathrm{Ca}^{2+}$ channel in adrenal chromaffin cells. J Neurosci 18:6230-6240.

Fenwick EM, Marty A, Neher E (1982) Sodium and calcium channels in bovine chromaffin cells. J Physiol (Lond) 331:599-635.

Gillis KD (1995) Techniques for membrane capacitance measurements. In: Single-channel recording, Ed 2, Chap 7 (Sakmann B, Neher E, eds), pp 155-198. New York: Plenum.

Gillis KD, Mossner R, Neher E (1996) Protein kinase C enhances exocytosis from chromaffin cells by increasing the size of the readily releasable pool of secretory granules. Neuron 16:1209-1220.

Herrington J, Solaro CR, Neely A, Lingle CJ (1995) The suppression of $\mathrm{Ca}^{2+}$ - and voltage-dependent outward $\mathrm{K}^{+}$current during mAChR activation in rat adrenal chromaffin cells. J Physiol (Lond) 485:297-318.

Hille B (2001) Ionic channels of excitable membranes, Ed 3. Sunderland, MA: Sinauer.

Hollins B, Ikeda SR (1996) Inward currents underlying action potentials in rat adrenal chromaffin cells. J Neurophysiol 76:1195-1211.

Horrigan FT, Bookman RJ (1994) Releasable pools and the kinetics of exocytosis in adrenal chromaffin cells. Neuron 13:1119-1129.

Huang LY, Neher E (1996) $\mathrm{Ca}^{2+}$-dependent exocytosis in the somata of dorsal root ganglion neurons. Neuron 17:135-145.

Kandel ER, Schwartz JH, Jessell TM (2000) Principles of neural science, Ed 4. New York: McGraw-Hill.

Kao LS, Schneider AS (1986) Calcium mobilization and catecholamine secretion in adrenal chromaffin cells. A Quin-2 fluorescence study. J Biol Chem 261:4881-4888.

Kidokoro Y, Ritchie AK (1980) Chromaffin cell action potentials and their possible role in adrenaline secretion from rat adrenal medulla. J Physiol (Lond) 307:199-216.

Klingauf J, Neher E (1997) Modeling buffered $\mathrm{Ca}^{2+}$ diffusion near the membrane: implications for secretion in neuroendocrine cells. Biophys J 72:674-690.

Lindau M, Neher E (1988) Patch-clamp techniques for time-resolved capacitance measurements in single cells. Pflügers Arch 411:137-146.

Mansvelder HD, Kits KS (2000) Calcium channels and the release of large dense core vesicles from neuroendocrine cells: spatial organization and functional coupling. Prog Neurobiol 62:427-441.

Martini RH (2001) Fundamentals of anatomy and physiology. Upper Saddle River, NJ: Prentice Hall.

Marty A, Neher E (1995) Tight-seal whole-cell recording. In: Single-channel recording, Ed 2, Chap 2 (Sakmann B, Neher E, eds), pp 31-51. New York: Plenum.

Neely A, Lingle CJ (1992) Two components of calcium-activated potassium current in rat adrenal chromaffin cells. J Physiol (Lond) 453:97-131.

Neher E (1998) Vesicle pools and $\mathrm{Ca}^{2+}$ microdomains: new tools for understanding their roles in neurotransmitter release. Neuron 20:389-399.

Neher E, Zucker RS (1993) Multiple calcium-dependent processes related to secretion in bovine chromaffin cells. Neuron 10:21-30.

Nowycky MC, Pinter MJ (1993) Time courses of calcium and calciumbound buffers following calcium influx in a model cell. Biophys $\mathrm{J}$ 64:77-91.

Otani S, Ben-Ari Y (1993) Biochemical correlates of long-term potentiation in hippocampal synapses. Int Rev Neurobiol 35:1-41.

Prakriya M, Lingle CJ (2000) Activation of BK channels in rat chromaffin cells require summation of $\mathrm{Ca}^{2+}$ influx from multiple $\mathrm{Ca}^{2+}$ channels. J Neurophysiol 84:1123-1135.

Sherman SM (2001) Tonic and burst firing: dual modes of thalamocortical relay. Trends Neurosci 24:122-126.

Smith C, Moser T, Xu T, Neher E (1998) Cytosolic $\mathrm{Ca}^{2+}$ acts by two separate pathways to modulate the supply of release-competent vesicles in chromaffin cells. Neuron 20:1243-1253.

Stewart AE, Foehring RC (2001) Effects of spike parameters and neuromodulators on action potential waveform-induced calcium entry into pyramidal neurons. J Neurophysiol 85:1412-1423.

Thomas P, Lee AK, Wong JG, Almers W (1994) A triggered mechanism retrieves membrane in seconds after $\mathrm{Ca}^{2+}$-stimulated exocytosis in single pituitary cells. J Cell Biol 124:667-675.

Tsodyks MV, Markram H (1997) The neural code between neocortical pyramidal neurons depends on neurotransmitter release probability. Proc Natl Acad Sci USA 94:719-723. 
Tsukada M, Aihara T, Mizuno M, Kato H, Ito K (1994) Temporal pattern sensitivity of long-term potentiation in hippocampal CA1 neurons. Biol Cybern 70:495-503.

Wightman RM, Jankowski JA, Kennedy RT, Kawagoe KT, Schroeder TJ, Leszczyszyn DJ, Near JA, Diliberto Jr EJ, Viveros OH (1991) Temporally resolved catecholamine spikes correspond to single vesicle release from individual chromaffin cells. Proc Natl Acad Sci USA 88:10754-10758.

Zhang C, Zhou Z (2002) $\mathrm{Ca}^{2+}$-independent but voltage-dependent secretion in mammalian dorsal root ganglion neurons. Nat Neurosci 5:425-430.

Zhang X, Aman K, Hokfelt T (1995) Secretory pathways of neuropeptides in rat lumbar dorsal root ganglion neurons and effects of peripheral axotomy. J Comp Neurol 352:481-500.

Zhou Z, Bers DM (2000) $\mathrm{Ca}^{2+}$ influx via the L-type $\mathrm{Ca}^{2+}$ channel during tail current and above current reversal potential in ferret ventricular myocytes. J Physiol (Lond) 523:57-66.

Zhou Z, Misler S (1995) Action potential-induced quantal secretion of catecholamines from rat adrenal chromaffin cells. J Biol Chem 270:3498-3505.

Zhou Z, Neher E (1993) Mobile and immobile calcium buffers in bovine adrenal chromaffin cells. J Physiol (Lond) 469:245-273.

Zucker RS (1989) Short-tem synaptic plasticity. Annu Rev Neurosci 12:13-31. 